\title{
RESPONSE TO METHYLPREDNISOLONE PULSE THERAPY IN REFRACTORY CHILDHOOD PYODERMA GANGRENOSUM: A CASE REPORT
}

\author{
P. Anila Sunandini' ${ }^{1}$ K. Venkata Chalam², G. Suryanarayana ${ }^{3}$, G. Ajay Kumar ${ }^{4}$, T. Priyadarshini ${ }^{5}$
}

\section{HOW TO CITE THIS ARTICLE:}

P. Anila Sunandini, K. Venkata Chalam, G. Suryanarayana, G. Ajay Kumar, T. Priyadarshini. "Response to Methylprednisolone Pulse Therapy in Refractory Childhood Pyoderma Gangrenosum: A Case Report". Journal of Evolution of Medical and Dental Sciences 2015; Vol. 4, Issue 11, February 05; Page: 1875-1878,

DOI: $10.14260 /$ jemds/2015/269

\begin{abstract}
Pyoderma gangrenosum is a rare, non-infectious, immune mediated, neutrophilic dermatosis associated with underlying systemic disease in $50 \%$ of cases. Brocq first described pyoderma gangrenosum in 1916.It is common in fourth and fifth decade. But childhood PG, reported was $4 \%$ percent. PG has been associated with systemic disorders like inflammatory bowel disease, arthritis, haematological disorders, autoimmune diseases, solid organ tumors, drugs etc. First line of management for PG is oral corticosteroids, dapsone and other sulphones. Other immunosuppresants are used as second line of treatment. Here we report a case of childhood PG not responding to conventional treatment but responded to methylprednisolone pulse therapy.
\end{abstract}

KEYWORDS: Refractory Pyoderma Gangrenosum, Methylprednisolone Pulse Therapy.

INTRODUCTION: Pyoderma gangrenosum is a rare neutrophilic dermatosis, occurring most frequently in fourth and fifth decade. Childhood cases of pyoderma gangrenosum are less prevalent, occurring around $4 \%$. Various drugs that decrease the immune reactivity are used to treat PG, of which first line are oral corticosteroids, dapsone and sulphones. Second line are other immunesuppresants and biologicals. We report a case of 7 year old boy who did not respond to conventional therapy but showed dramatic response to methylprednisolone pulse therapy.

CASE REPORT: A seven year old male child came with chief complaints of ulcer over left elbow and left thigh since 2 days. Initially the complaint started as painful pustule which ulcerated in a span of 2 days, ulcers are extremely painful. The patient was febrile.

Two years back patient had similar complaint of non-healing painful ulcers for which he attended pediatric surgery department. Autologous Split skin grafting was done for the non-healing ulcers, patient developed similar ulcers at the donor site, canula site. Then patient was referred to dermatology department. From the clinical history and pathergy reaction provisional diagnosis of pyodermas gangrenosum was made. Biopsy was taken from the edge of the ulcer. Histopathology showed loss of epidermis with dense neutrophilic infiltration in dermis. All other investigations were normal. Diagnosis of pyodermas gangrenosum was confirmed and the patient was treated with prednisolone 20mg, dapsone 25mg OD. Ulcers healed in a span of 4 weeks with scarring. Prednisolone was tapered and stopped. Dapsone was continued till 2014 May. Patient stopped dapsone two months back and developed ulcerative lesions.

Examination of the patient: Patient is pale looking. An ulcer of Size $8 x 6 \mathrm{~cm}$, present over Left elbow, with erythematous violaceous infiltrated margins and necrotic slough, edge was undermined and rolled out at places. Similar ulcer present over Left thigh. 
Repeated pus culture did not reveal growth of any pathogenic organism, Blood culture isolated E. Coli which was sensitive to amikacin, Lab investigations showed hemoglobin was $8 \mathrm{~g} \%$; Complete blood count showed a leucocytosis (total count 19,000/cu mm with neutrophils 68\%, lymphocytes $30 \%$, monocytes $0 \%$, eosinophils $2 \%$ ) with thrombocytosis $(611,000 / \mathrm{cu} \mathrm{mm})$. A peripheral smear showed microcytic hypochromic anemia. Blood tests for urea, creatinine, electrolytes, liver function tests, sugar, VDRL, RA factor, HIV, serum electrophoresis for proteins and immune electrophoresis did not reveal any abnormality. Routine examination of urine and stools also did not show any abnormality. X-ray chest and ultrasound of abdomen, sigmoidoscopy also did not reveal any pathology.

Skin biopsy showed loss of overlying epidermis at places, covered with fibrin and necrotic material, dermis showed diffuse dense infiltrate of neutrophils [Figure 1d].

Systemic examination was normal: Diagnosis of pyoderma gangrenosum was confirmed and the patient was put on 20mg Prednisolone and 25mg Dapsone, inj. Amikacin 300mg iv BD for ten days but lesions increased in size with peripheral extention and central healing and increased in number, Patient also developed pathergy at cannula site [Figure 1a, 1b, 1c].

Cyclosporine $50 \mathrm{mg}$ /day added along with prednisolone $30 \mathrm{mg}$ and dapsone $25 \mathrm{mg}$ and given for 18 days. More number of pustular lesions appeared which subsequently ulcerated. [Figure 2a, 2b].

Finally patient was treated with methyl prednisolone pulse $300 \mathrm{mg}(15 \mathrm{mg} / \mathrm{kg})$ in $150 \mathrm{ml}$ of $5 \%$ dextrose /day for 3 consecutive days, dramatic response was noted with complete resolution of ulcers which healed with scarring. [Figure 3].

Prednisolone was gradually tapered and patient was discharged after 3 weeks. Patient developed small ulcer at the margin of scar after two weeks which was managed with topical tacrolimus $0.1 \%$ along with systemic therapy, now patient was on prednisolone $10 \mathrm{mg}$ OD, dapsone $25 \mathrm{mg}$ OD, cyclosporine 50mg OD, topical tacrolimus $0.1 \%$.

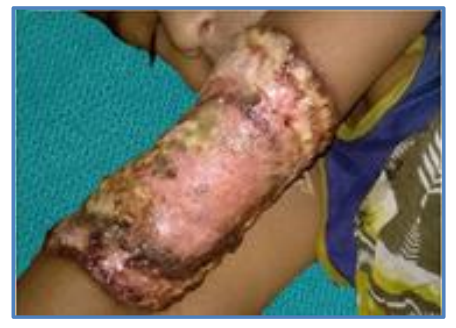

Fig. $1 \mathrm{a}$

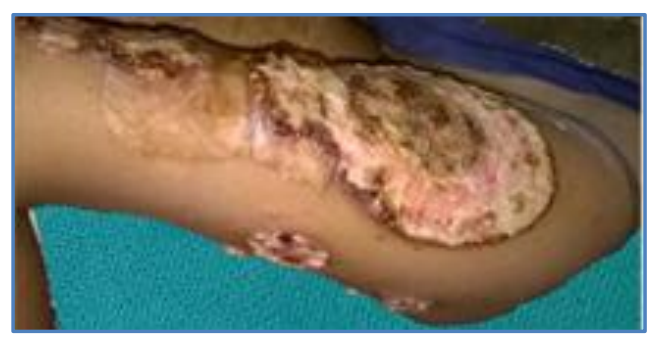

Fig. 1 b

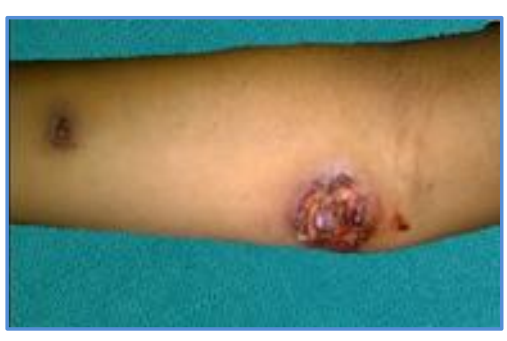

Fig. 1c

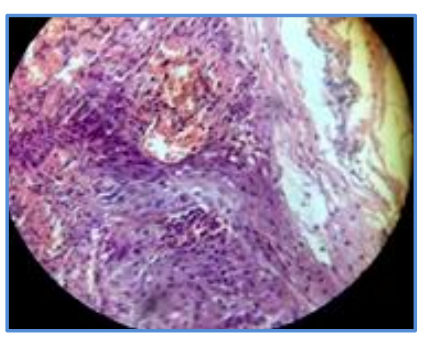

Fig. 1d 


\section{CASE REPORT}

\section{Figure 1:}

a) Ulcer over left elbow.

b) Ulcer over left thigh.

c) pathergy at cannula site.

d) dense neutrophilic infiltration in dermis.

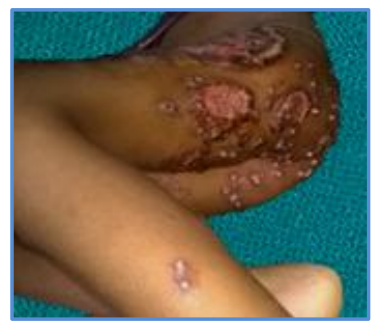

Fig. 2a

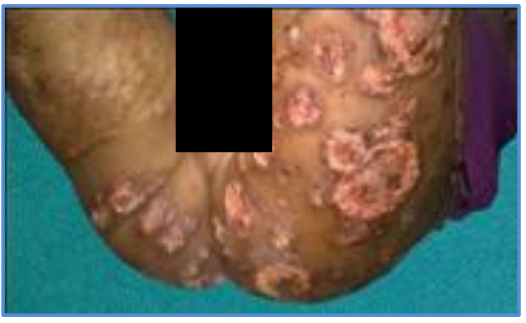

Fig. 2b

\section{Figure 2:}

a) Multiple pustules.

b) Ulcerated.

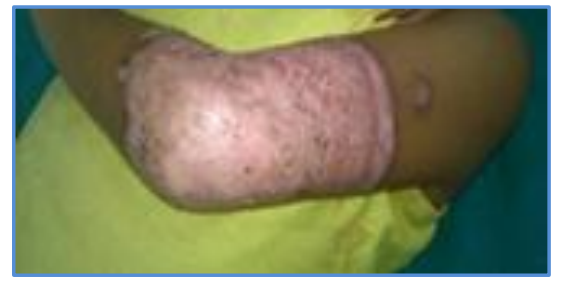

Fig. 3a

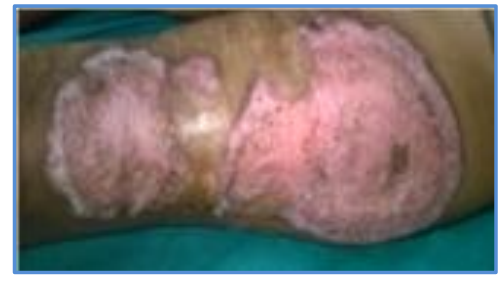

Fig. $3 b$

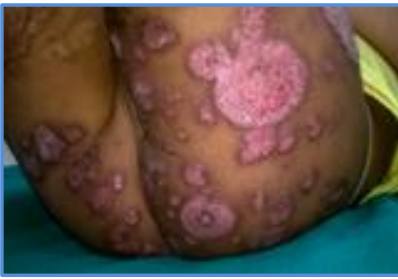

Fig. 3c

Figure 3: ulcers healing with scaring.

DISCUSSION: Pyoderma gangrenosum is a neutrophilic dermatosis, commonly seen in the fourth to fifth decade of life. Only about $4 \%$ of the patients are children and infants.[1] Although the pathogenesis of pyoderma gangrenosum is unknown, immunologic aberrations of neutrophil granulocytes seem to be important.[2] In about $50 \%$ of the cases, it may be associated with a variety of systemic conditions like inflammatory bowel disease, rheumatoid arthritis, hematological malignancies etc. Sometimes it may be an isolated occurrence, as in our case.[3] Development of new lesions at the injection sites in the present case suggested the phenomenon of pathergy.[4,5] Initially patient responded to combination of perdnisolone and dapsone, Glass et al[6] have also observed good results with similar combination therapy. Aggressive cases may require methyl prednesolone pulse,[7] or a combination of systemic treatments.[8] Topical immunosuppressants can be effective in mild or early cutaneous lesions.[2] The long-term outcome for patients with pyodermas gangrenosum remains unpredictable. Recurrence rates up to $46 \%$ are seen regardless of the treatment prescribed. ${ }^{[9]}$ Split skin grafts have been seen to be helpful after ensuring that the disease is quiescent to avoid pathergy.[10] 


\section{REFERENCES:}

1. Graham JA, Hansen KK, Rabinowitz LG, Esterly NB. Pyoderma gangrenosum in infants and children. Pediatr Dermatol 1994; 11: 10-7.

2. Petering $\mathrm{H}^{1}$, Kiehl $\mathrm{P}$, Breuer C, Kapp A, Werfel T. Pyoderma gangrenosum: successful topical therapy with tacrolimus (FK506). Hautarzt. 2001 Jan; 52 (1): 47-50. [Article in German]

3. Sandhu K, Handa S, Kanwar AJ.Idiopathic pyoderma gangrenosum in a child. Pediatr Dermatol 2004 May-Jun; 21 (3): 276-7.

4. Powell FC, Perry HO. Pyoderma gangrenosum in childhood. Arch Dermatol 1984; 120: 757-61.

5. ML Khatri, M Shafi, M Benghazil, A Machina, Sassi: Pyoderma gangrenosum in childhood Indian Journal of Dermatology, Venereology, and Leprology, Year 1995, Volume 61.

6. Glass TA, Bancila E, Milgraum S. Pyoderma gangrenosum in infancy: The youngest reported patient. J Am Acad Dermatol 1991; 25: 109-10.

7. Sharma R, Borkar MA, Oke MA, Wilkinson AR, Maimoon SA. Pyoderma gangrenosum in a two year-old child. Indian J Dermatol Venereol Leprol. 2007 Jul-Aug; 73 (4): 268-70.

8. Gettler S, Rothe M, Grin C, Grant-Kels J. Optimal treatment of pyoderma gangrenosum. Am J Clin Dermatol 2003; 4: 597-608.

9. Mlika RB, Riahi I, Fenniche S, Mokni M, Dhaoui MR, Dess N, et al. Pyoderma gangrenosum: A report of 21 cases. Int J Dematol 2002; 41: 65-8.

10. Cliff S, Holden CA, Thomas PR, Marsden RA, Harland CC. Split skin grafts in the treatment of Pyoderma gangrenosum. Dermatol Surg 1999; 25: 299-302.

\section{AUTHORS:}

1. P. Anila Sunandini

2. K. Venkata Chalam

3. G. Suryanarayana

4. G. Ajay Kumar

5. T. Priyadarshini

\section{PARTICULARS OF CONTRIBUTORS:}

1. Professor \& HOD, Department of Dermatology, A. M. C, Vizag.

2. Assistant Professor, Department of Dermatology, A. M. C, Vizag.

3. Assistant Professor, Department of Dermatology, A. M. C, Vizag.

4. Assistant professor, Department of Dermatology, A. M. C, Vizag.
5. Junior Resident, Department of Dermatology, A. M. C, Vizag.

\section{NAME ADDRESS EMAIL ID OF THE} CORRESPONDING AUTHOR:

Dr. P. Anila Sunandini,

Professor \& HOD,

Department of DVL,

Andhra Medical College,

Vizag.

E-mail: gppatnala@yahoo.co.in

Date of Submission: 06/01/2015.

Date of Peer Review: 07/01/2015.

Date of Acceptance: 27/01/2015.

Date of Publishing: 05/02/2015. 